\title{
$\mathrm{Ni-P}$ 無電解めっきにおける Pd に代わる 活性化剂としての蒸着亜鉛の応用
}

\author{
津留 豊*，持永光爾*，久米道之**，大八木八七*** \\ *九州工業大学 工学部（干804-8550 福岡県北九州市戸畑区仙水町 1-1） \\ **名古屋市工業研究所（干456-0058 愛知県名古屋市熱田区 3-4-41） \\ ***石川金属工業株（T802-8512 福岡県北九州市小倉北区赤坂海岸 2-1）
}

\section{Application of Vapor-plated Zinc as a Substitute for Palladium Catalyst in the Nickel-Phosphorus Electroless Plating}

\author{
Yutaka TSURU*, Kouji MOCHINAGA*, Michiyuki KUME** and Yashichi OOYAGI***
}

\author{
${ }^{*}$ Faculty of Engineering, Kyushu Institute of Technology (1-1, Sensui-cho, Tobata-ku, Kitakyusyu-shi, Fukuoka \\ 804-8550) \\ ${ }^{* *}$ Nagoya Municipal Industrial Research Institute (3-4-41, Rokuban, Atsuta-ku, Nagoya-shi, Aichi 456-0058) \\ *** Ishikawa Metal Industry Co., Ltd. (2-1, Akasaka-kaigan, Kokurakita-ku, Kitakyusyu-shi, Fukuoka 802-8512)
}

\begin{abstract}
Colloidal mixing hydroxide, which consists of nickel ions and copper ions, was allowed to adsorb onto an ABS resin. After making these colloids dry up, carbon and then zinc were deposited on it using the physical vapor deposition technique. Articles containing the colloids, carbon and zinc were used as substitutes for palladium catalyst in the electroless nickel plating.

In the $90^{\circ}$ peeling strength test, all of these electroless plated nickel films showed about $200 \mathrm{~kg} / \mathrm{m}$ compared with the peeling strength obtained by the conventional method which couples tin $(2+)$ as a sensitizer with palladium $(2+)$ as an activator. The strong adhesion resulted in a cohesive fracture of the ABS resin during the peeling test. Such a result shows the following; (1) the colloids invaded and adsorbed into the etching holes which occurred in the etching of the ABS resin by the chromic acid, (2) the colloids were reduced to nickel and copper by the electrons produced by dissolution of the zinc in the plating solution, and then the nickel and copper worked as an anchor for the plated nickel films. Also the nickel naturally worked as a self-catalyst for continuing the electroless nickel plating.
\end{abstract}

Key Words : Electroless Plating, Colloidal Solution, Vapor Deposition, Peeling Strength, ABS Resin

\section{1. 緒言}

プラスチックスおよびセラミックスのような絶縁物への無 電解めっきでは，反応を開始させるために触媒核が必要であ り，一般にスズーパラジウムの組み合わせによる触媒核形成 反応が利用されている(1),2)。しかし，パラジウムは各種化学 反応の水素化あるいは還元触媒としても優れた素材であり, 近年供給不足のため価格高騰の傾向にある。このため，パラ ジウムに代わる安価な無電解めつき用触媒が求められている。

ところで, 無電解めっきに抢いて, ニッケルめっきでは ニッケルが，銅めっきでは銅がめっき持続のための触媒とし て機能する。このことは，素材上にこれら金属核を前もって 付与しておけば，パラジウム触媒を用いなくてもそれぞれの 無電解めつきが可能になることを意味する。

本研究では，ABS 樹脂板に二ッケルおよび銅イオンから なる混合水酸化物コロイド3) を吸着させ，その上へ物理的に カーボンおよび亜鉛を均一に蒸着, その後これら吸着コロイ ドを蒸着覀鉛を犠牲陽極に用いて金属にまで還元 ${ }^{4)} し ，$ 無電
解ニッケルめつきのための自己触媒とともに，めつき膜の密 着力を高めるアンカーとして機能させることを試みた。

\section{2. 実験方法}

図 1 は, ABS 樹脂板の前処理からニッケルめっき後の 90

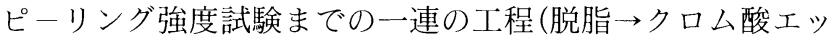

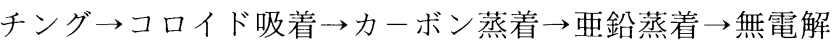
ニッケルめつき 銅めつき $\rightarrow$ ピーリング試験) とその操作条 件を示す。ここで蒸着カーボンは, (1)蒸着亜鉛の均一な付着 の促進，および(2)亜鉛の溶解に際して生じる電子を下層の吸 着コロイドへ効果的に移動させるために用いた。一方，この ようなカーボン蒸着法は, その良導電性および表面形態追従 性を生かして, 走査型電子顕微鏡 (SEM) による絶縁物表面 の高倍率観察のため広く利用されている。また, 実験は比較 のため, 図 1 の工程からコロイド吸着処理を除いた場合, お よび表 1 の溶液と操作条件を用いた従来のスズーパラジウム 法による活性化処理をも実施した。

基材のプラスチックスには，厚み $3 \mathrm{~mm}$ の市販 $\mathrm{ABS}$ 樹脂 
板(新神戸電気(秼)製 ナチユラル)を $100 \times 10 \times 3 \mathrm{~mm}$ に加工 して用いた。また，コロイド溶液には表 2 に示すコロイド $\mathrm{A}(\text { 硫酸ニッケルー硫酸銅一酒石酸, } \mathrm{pH} 7.8)^{3)}$ およびコロイ ド $\mathrm{B}(\text { 硫酸ニッケルー硫酸銅一スクロース, } \mathrm{pH} 12)^{5)}$ の 2 種 類を利用した。ABS 樹脂板に吸着させたコロイド上への カーボンおよび亜鉛の蒸着は, 真空蒸着法(PVD)で行い, それぞれの蒸着厚みはカーボンが $10 \mathrm{~nm}$ 程度, 亜鉛が $20 \mathrm{~nm}$

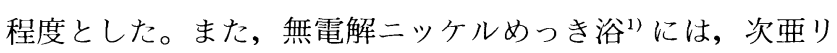
ン酸ナトリウムを還元剤とする $\mathrm{pH}$ が 5.4 と 6.0 の 2 種類の 溶液を用いた。

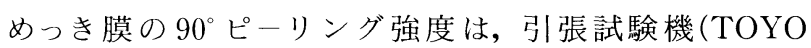
BALDWIN 製 STM-T-100 BP)を用いて測定した6)。この ピーリング強度試験では, ニッケルめっき膜の補強のため, その上へさらに $50 \mu \mathrm{m}$ の電気銅めっきを行った。ピーリン グ試験後の ABS 樹脂板表面およびこれと対をなすはく離 ニッケルめっき膜裏面の形態は, 走査型電子顕微鏡 $(\mathrm{JEOL}$ 製 TCXA-733)を用いて観察した。

\section{3. 結果および考察}

\section{1 コロイド吸着の効果}

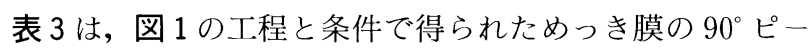

\section{Process Bath composition Condition}

\begin{tabular}{|c|c|c|c|c|}
\hline Degreasing & $\mathrm{NaOH}$ & $400 \mathrm{~g} / \mathrm{dm}^{3}$ & $65^{\circ} \mathrm{C}$ & $5 \min$ \\
\hline \multicolumn{5}{|c|}{$\downarrow$ Rinsing by flowing water } \\
\hline Etching & $\begin{array}{l}\mathrm{CrO}_{3} \\
\mathrm{Cr}_{2} \mathrm{O}_{3} \\
\mathrm{H}_{2} \mathrm{SO}_{4}\end{array}$ & $\begin{array}{r}400 \mathrm{~g} / \mathrm{dm}^{3} \\
10 \mathrm{~g} / \mathrm{dm}^{3} \\
400 \mathrm{~g} / \mathrm{dm}^{3}\end{array}$ & $65^{\circ} \mathrm{C}$ & $5 \min$ \\
\hline \multicolumn{5}{|c|}{$\downarrow$ Rinsing by flowing water } \\
\hline Neutralization & $\mathrm{HCl}$ & $50 \mathrm{dm}^{3} / \mathrm{m}^{3}$ & room temp. & $5 \min$ \\
\hline \multicolumn{5}{|c|}{$\downarrow$ Rinsing by flowing water } \\
\hline Adsorption & $\begin{array}{l}\text { Two kinds of sol } \\
\text { table } 2 \text { (colloid A }\end{array}$ & $\begin{array}{l}\text { s depicted in } \\
\text { oid B) }\end{array}$ & $\begin{array}{l}30 \mathrm{C} \\
\text { with stirring }\end{array}$ & $\mathrm{g}^{10 \mathrm{~min}}$ \\
\hline \multicolumn{5}{|c|}{$\downarrow$ Rinsing by flowing water and dry } \\
\hline Vapor plating & Carbon & & $\sim 10 \mathrm{~nm}$, & $10^{-3}$ torr \\
\hline \multicolumn{5}{|c|}{$\downarrow$} \\
\hline Vapor plating & Zinc & & $\sim 20 \mathrm{~nm}, \quad \sim$ & $10^{-3}$ torr \\
\hline \multicolumn{5}{|c|}{$\downarrow$} \\
\hline $\begin{array}{l}\text { Electroless plating } \\
\text { of Ni-P alloy }\end{array}$ & \begin{tabular}{|l}
$\mathrm{NiSO}_{4} \cdot 6 \mathrm{H}_{2} \mathrm{O}$ \\
$\mathrm{H}_{2} \mathrm{NCH}_{2} \mathrm{COOH}$ \\
$\mathrm{NaH}_{2} \mathrm{PO}_{2} \cdot \mathrm{H}_{2} \mathrm{O}$
\end{tabular} & $\begin{array}{l}25 \mathrm{~g} / \mathbf{d m}^{3} \\
30 \mathrm{~g} / \mathbf{d m}^{3} \\
20 \mathrm{~g} / \mathbf{d m}^{3}\end{array}$ & $\begin{array}{c}60{ }^{\circ} \mathrm{C} \\
\text { pH5.4 or } 6.0\end{array}$ & $\begin{array}{c}60 \mathrm{~min} \\
0 \mathrm{by} \mathrm{NaOH}\end{array}$ \\
\hline \multicolumn{5}{|c|}{$\downarrow$ Rinsing by flowing water } \\
\hline $\begin{array}{l}\text { Electroplating of } \\
\mathrm{Cu}\end{array}$ & \begin{tabular}{|l|}
$\mathrm{CuSO}_{4} \cdot 5 \mathrm{H}_{2} \mathrm{O}$ \\
$\mathrm{H}_{2} \mathrm{SO}_{4}$ \\
\end{tabular} & $\begin{array}{l}200 \mathrm{~g} / \mathrm{dm}^{3} \\
50 \mathrm{~g} / \mathrm{dm}^{3}\end{array}$ & $\begin{array}{l}30{ }^{\circ} \mathrm{C} \\
5 \mathrm{~A} / \mathrm{dm}^{2}\end{array}$ & $45 \min$ \\
\hline
\end{tabular}

Fig. 1 Flowchart of the electroless plating of Ni-P alloy and the $90{ }^{\circ}$ peeling strength test.

Table 1 Bath composition of a sensitizer and an activator.

\begin{tabular}{c|lr|c}
\hline Bath & \multicolumn{2}{|c|}{ Composition } & Condition \\
\hline \multirow{2}{*}{ Sensitizer } & $\mathrm{SnCl}_{2}$ & $24 \mathrm{~g} / \mathrm{dm}^{3}$ & $25^{\circ} \mathrm{C}$ \\
& $\mathrm{HCl}$ & $12 \mathrm{dm}^{3} / \mathrm{m}^{3}$ & $2 \mathrm{~min}$ \\
\hline \multirow{2}{*}{ Activator } & $\mathrm{PdCl}_{2}$ & $0.2 \mathrm{~g} / \mathrm{dm}^{3}$ & $25^{\circ} \mathrm{C}$ \\
& $\mathrm{HCl}$ & $2 \mathrm{dm}^{3} / \mathrm{m}^{3}$ & $2 \mathrm{~min}$ \\
\hline
\end{tabular}

リング強度測定結果を示す。無電解めっき反応は, いずれの 場合も速やかに進行し，ピーリング強度が，コロイドの種類 およびめっき浴の $\mathrm{pH}$ に依存することなく $200 \mathrm{~kg} / \mathrm{m}$ 程度で あった。このような結果は, 蒸着亜鉛がめっき浴から亜鉛上 に吸着したニッケルイオンを金属ニッケルにまで還元(置換 析出)し，これらニッケルがめつき持続のための自己触媒と して機能したことを示している。

ところで, 同じ ABS 樹脂板を用い, 図 1 の脱脂, クロム 酸エッチングの後, 表 1 の感受性化一活性化のスズーパラジ ウム法で作製したニッケルめっき膜のピーリング強度は, $220 \pm 20 \mathrm{~kg} / \mathrm{m}$ であった ${ }^{7), 8)}$ 。以上の結果は, 水酸化物コロイ ド吸着, カーボン蒸着そして亜鉛蒸着の組み合わせによる活 性化法が, 従来の塩化スズー塩化パラジウム法と同程度の ピーリング強度を達成できる活性化法であることを示してい る。

一方, 図 1 の工程からコロイド吸着処理を除いて得られた めっき膜のピーリング強度は, 表 4 のようにその平均值が $105 \mathrm{~kg} / \mathrm{m}$ と, コロイドを吸着させた前者に比べ $1 / 2$ 程度で あった。このことは, ABS 樹脂板へのコロイド吸着が, $\mathrm{ABS}$ 樹脂とニッケルめっき膜間の密着力向上に, 大きな効 果をもたらしたことを示唆する。

亜鉛蒸着およびニッケルめつき後の外観は, ABS 樹脂板 にコロイドを吸着させた後カーボンおよび亜鉛を蒸着したも のでは, 蒸着亜鉛およびニッケルめっき膜ともに付きまわり が良好で, かつ金属光沢であった。一方, コロイド吸着処理 を除いたものでは, 蒸着カーボンおよび蒸着亚鉛の付きまわ

Table 2 Bath composition of colloid A and colloid B.

\begin{tabular}{c|lr|c}
\hline Colloid & \multicolumn{2}{|c|}{ Bath composition } & Condition \\
\hline \multirow{3}{*}{ Colloid A } & $\mathrm{NiSO}_{4} \cdot 6 \mathrm{H}_{2} \mathrm{O}$ & $26.3 \mathrm{~g} / \mathrm{dm}^{3}$ & $\mathrm{pH} 7.8$ \\
& $\mathrm{CuSO}_{4} \cdot 5 \mathrm{H}_{2} \mathrm{O}$ & $2.5 \mathrm{~g} / \mathrm{dm}^{3}$ & (by $5 \mathrm{M} \mathrm{NaOH})$ \\
& $\mathrm{C}_{4} \mathrm{H}_{6} \mathrm{O}_{6}$ & $3.0 \mathrm{~g} / \mathrm{dm}^{3}$ & \\
\hline \multirow{3}{*}{ Colloid B } & $\mathrm{NiSO}_{4} \cdot 6 \mathrm{H}_{2} \mathrm{O}$ & $2.0 \mathrm{~g} / \mathrm{dm}^{3}$ & $\mathrm{pH} 12$ \\
& $\mathrm{CuSO}_{4} \cdot 5 \mathrm{H}_{2} \mathrm{O}$ & $10.0 \mathrm{~g} / \mathrm{dm}^{3}$ & (by $5 \mathrm{M} \mathrm{NaOH})$ \\
& $\mathrm{C}_{12} \mathrm{H}_{22} \mathrm{O}_{11}$ & $20.0 \mathrm{~g} / \mathrm{dm}^{3}$ & \\
\hline
\end{tabular}

Table 3 Relationships between the peeling strength of plating films and the bath conditions in Figure 1.

\begin{tabular}{l|ccccc}
\hline \multirow{2}{*}{ Bath conditions } & \multicolumn{5}{|c}{$90^{\circ}$ peeling strength $(\mathrm{kg} / \mathrm{m})$} \\
\cline { 2 - 6 } & exp. 1 & exp. 2 & exp. 3 & exp. 4 & ave. \\
\hline $\begin{array}{l}\text { Colloid A and } \\
\text { plating bath pH 5.4 }\end{array}$ & 183 & 190 & 207 & 217 & 199 \\
\hline $\begin{array}{l}\text { Colloid A and } \\
\text { plating bath pH 6.0 }\end{array}$ & 187 & 197 & 200 & 197 & 195 \\
\hline $\begin{array}{l}\text { Colloid B and } \\
\text { plating bath pH 6.0 }\end{array}$ & 190 & 197 & 207 & 200 & 199 \\
\hline
\end{tabular}

Table 4 The peeling strength of plating films obtained without adsorption of the colloids on the ABS resin in Figure 1.

\begin{tabular}{c|cccccc}
\hline \multirow{2}{*}{ Bath condition } & \multicolumn{5}{|c}{$90^{\circ}$ peeling strength $(\mathrm{kg} / \mathrm{m})$} \\
\cline { 2 - 6 } & exp. 1 & exp. 2 & exp. 3 & exp. 4 & ave. \\
\hline Plating bath pH 6.0 & 97 & 103 & 113 & 105 & 105 \\
\hline
\end{tabular}



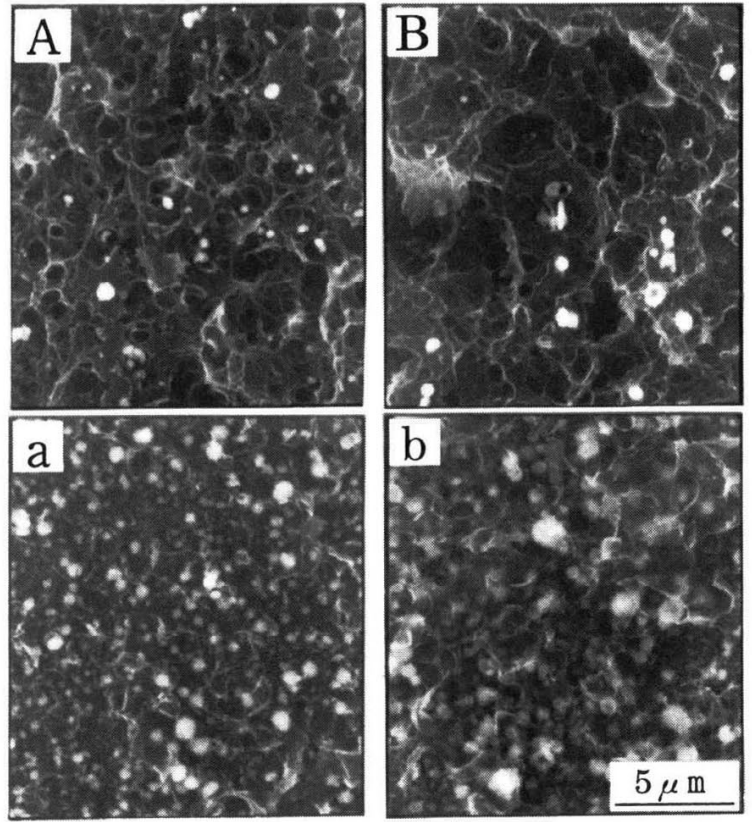

Fig. 2 SEM photographs of the surface of an ABS resin and of Ni-P film facing the ABS resin.

The left side are a pair of the ABS resin (A) and Ni-P film (a) having the peeling strength of $97 \mathrm{~kg} / \mathrm{m}$. The right side are a pair of the ABS resin (B) and $\mathrm{Ni}-\mathrm{P}$ film (b) having the peeling strength of $207 \mathrm{~kg} /$ $\mathrm{m}$.

りが不十分で，ニッケルめっき不良が ABS 樹脂板の両端部 に生じた。

このように ABS 樹脂に吸着させた水酸化物コロイドが, 蒸着カーボンおよび蒸着亜鉛の付きまわりを促進させ，ニッ ケルめっき膜の密着力を高める効果は, 乾式処理における付 きまわり改善のための一つの方法と考えられるが，その理由 は明らかでなく今後の検討を要する。

\section{2 めっき膜はく離面の形態}

図 2 は，ピーリング強度試験後の ABS 樹脂表面と，これ と対をなすはく離ニッケル面の写真を示している。写真は, (1)右の列が, ABS 樹脂板にコロイド B を吸着させ, カー ボンおよび亜鉛蒸着の後, ニッケルめっきして得られたピー リング強度が $207 \mathrm{~kg} / \mathrm{m}$ の試料，および(2)左の列が，他の 条件は同じであるがコロイド吸着なしで得られたピーリング 強度 $97 \mathrm{~kg} / \mathrm{m}$ の試料についてのものである。ただし, 無電 解ニッケルめっき浴の $\mathrm{pH}$ はいずれの場合も 6.0 とした。

写真で，ピーリング強度の弱い後者に比ベピーリング強度 の強い前者では, $\mathrm{ABS}$ 樹脂表面に大きな山凸が現れ，はく 離ニッケル面には素地 $\mathrm{ABS}$ 樹脂の凝集破壊に基づく $\mathrm{ABS}$ 樹脂片の移動が観察された。
以上の結果は以下のことを示唆している。(1)ニッケルお よび銅イオンからなる混合水酸化物コロイドが，クロム酸に よる ABS 樹脂のエッチングで生じたエッチング痕にまで侵 入そして吸着した。（2）これらコロイドは, 蒸着覀鉛の溶解 時に生じた電子によって金属ニッケルおよび銅にまで還元さ れ，ニッケルめっき膜のアンカーとして機能した。さらに， (3)表 2 において，コロイドの種類およびめっき浴の $\mathrm{pH}$ に 依存することなく，ピーリング強度がいずれの場合も 200 $\mathrm{kg} / \mathrm{m}$ 前後となった原因は, ABS 樹脂とニッケルめっき膜 間の密着強さが, $\mathrm{ABS}$ 樹脂板の凝集破壊強度を越えたため である。

\section{4. 結 論}

$\mathrm{ABS}$ 樹脂の無電解ニッケルめつきにおいて，パラジウム 触媒を使用しない活性化法が，ニッケルおよび銅イオンから なる混合水酸化物コロイドを吸着させ, 乾燥後さらにその上 へカーボンおよび亜鉛を蒸着することで可能となった。

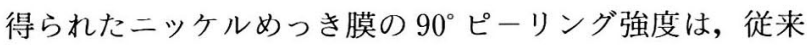
のスズーパラジウム活性化法と同程度で, 素地 ABS 樹脂に 凝集破壊をもたらすような $200 \mathrm{~kg} / \mathrm{m}$ を達成した。また，吸 着コロイドは亜鉛よって還元され，ABS樹脂とニッケル めつき膜間の密着力を高めるアンカーとして作用した。

\section{謝 辞}

本研究の実施にあたり，平成 12 年の中小企業創造基盤技 術研究事業(プロゼェクトNo.11-34)の費用の一部を使用し た。また，EPMA 測定およびカーボンと亜鉛蒸着に際して， 九州工業大学・機器分析センターの白石勝治技官の協力を得 た。ここに記して謝意を表する。

(Received May 30, 2001 ; Accepted October 24, 2001)

\section{文献}

1 ）たとえば, 金属表面技術協会 ; 金属表面技術便覧，p. 476（日 刊工業新聞社, 1976)

2 ) たとえば, M. Paunovic, M. Schlesinger; Fundamentals of Electrochemical Deposition, p. 133 (John Wiley \& Sons, 1998)

3 ) 岩井正雄, 真嶋 宏, 粟倉泰弘; 金属表面技術, 38, 234（1987）

4 ) たとえば, 玉虫伶太 ; 電気化学, p. 299 (東京化学同人, 1967)

5 ) А. Б. ЗИЛЬБЕРМАН, Б. С. ФРИДМАН, М. С. ГУСЕВА, М. А. ЕФИМОВ, В. Е. АРХИРЕЕВ ; Пласт. массы, (2) 52-56 (1989)

6 ）石橋純一, 小林 健, 市川卓美, 本間英夫：エレクトロニクス 実装学会誌，1，483（1998）

7 ）津留 豊, 藤田由香里, 久米道之, 大八木八七；表面技術協会 第 102 回講演大会要旨集, p. 32 (2000)

8 ）津留 豊, 藤田由香里, 久米道之, 大八木八七；表面技術, 52 , 576 (2001) 